\title{
Perceptions of academic staff about mentoring in a Faculty of Dentistry in a public university in South Africa
}

SADJ July 2021, Vol. 76 No. 6 p309 - p314

\author{
SL Amosun', GAVM Geerts², R Basson ${ }^{3}$
}

\section{ABSTRACT}

\section{Introduction}

Mentoring programs contribute to the development and retention of academics in dental education.

\section{Objectives}

To describe the perceptions of academic staff of the Faculty of Dentistry, University of the Western Cape, South Africa, about a funded pilot mentoring process.

\section{Design}

Cross-sectional, purposive sampling qualitative design.

\section{Methods}

Twenty mentees who had engaged in the funded mentoring process were targeted for semi-structured interviews, to describe their perceptions about the ongoing mentorship process, experiences in other mentoring processes, and expectations about future formal mentoring in the faculty. Quantitative data was analysed descriptively, while content analysis of the qualitative data was performed to identify themes.

\section{Findings and conclusions}

Perceptions of eight mentees, aged 37 to 59 years and spent between 3 and over 20 years in the faculty, were categorized into two themes - 'A welcome initiative' and

\section{Author affiliations:}

1. Seyi Ladele Amosun: BSc Physiotherapy, PhD, PGDip Health Professions Education, Mentor, Faculty of Dentistry, University of the Western Cape, Cape Town, South Africa.

ORCID Number: 0000-0001-7358-227X

2. Greta AVM Geerts: $B C h D, P D D, M C h D, P h D$, Deputy Dean for Research and Higher Degrees, Faculty of Dentistry, University of the Western Cape, Cape Town, South Africa.

ORCID Number: 0000-0002-6324-4251

3. Reneda Basson: MA Research Psychology, Research Administrator, Faculty of Dentistry, University of the Western Cape, Cape Town, South Africa.

ORCID Number: 0000-0002-2117-1605

Corresponding author: Seyi Ladele Amosun

Faculty of Dentistry, University of the Western Cape, Tygerberg Oral Health Centre, Tygerberg, South Africa.

Email: samosun@uwc.ac.za

Author contributions:

1. Seyi L Amosun: Conceptualisation, reviewed analysed data, preparation of initial and final draft of manuscript - 35\%

2. Greta AVM Geerts: Conceptualisation, resourced grant for project, reviewed analysed data, contributed to and reviewed fina draft of manuscript - 35\%

3. Reneda Basson: Project administration, reviewed analysed data, contributed to and reviewed final draft of manuscript - $30 \%$

'Mentorship seen as a holistic experience'. The program provided the much-needed space where mentees felt they could seek guidance for their development.

Expectations from a future formal program included assistance in meeting institutional and personal demands. Participants' expectations were broader than what the pilot program offered, though the benefits reported were similar to earlier studies.

\section{Keywords}

Mentoring, academic staff, faculty development, oral health, dental faculty.

\section{INTRODUCTION}

More than twenty-five years in the post-apartheid era, the government of the Republic of South Africa (RSA) continues to seek ways to reverse the past inequities in higher education by introducing the National Development Plan (NDP) as part of the transformation process..$^{1,2}$ The Department of Higher Education and Training (DHET) was mandated to achieve the following goals, among others, by 2030 - increase the (i) percentage of PhD qualified academic staff from current $46 \%$ to over $75 \%$; (ii) number of doctoral graduates per million from current 46 to 100; and (iii) publication count, which increased from approximately 5500 in 1995 to 15542 in $2014 .{ }^{3}$

The University of the Western Cape (UWC) is one of the 26 universities that benefited from the University Capacity Development Grant (UCDG), funded by the DHET to assist with capacity development of academic staff. ${ }^{4}$ In 2018, the DHET introduced the University Capacity Development Program (UCDP) for the development of students, staff, and academic programs. ${ }^{5}$

A portion of the UCDG was allocated to the Existing Academic Staff Capacity Enhancement Program (EASCEP) to support the completion of postgraduate studies (MSc, $\mathrm{PhD}$, post-doctoral) ${ }^{6}$ and increase publication count. The Deputy Vice Chancellor (Research and Innovation) manages the process at UWC, and in 2019 mentors were appointed on a part-time basis for each of the seven faculties. The Deputy Dean Research and Postgraduate Programs supervises the processes in the Faculty of Dentistry. 
Though labelled a previously disadvantaged university which operated under severe financial and social constraints, UWC has contributed towards democracy and transformation by providing access to students from previously disadvantaged communities. ${ }^{7,8}$ By widening access, the university experienced exponential growth resulting in large classes with underprepared students and often inadequate facilities. ${ }^{9}$ These factors contributed to the challenges in attracting and keeping competent academics who could mentor junior academic staff to succeed in the areas of teaching, research, and academic administration, among others. ${ }^{10}$

While the first dental education program in the country was established in 1925, ${ }^{11}$ there were concerns that the dental needs of a heterogeneous community were not being fully met. ${ }^{12}$ The dental faculty at UWC was established in $1974^{13}$ to broaden access into the profession ${ }^{12,14}$ and address the shortage of oral health professionals. ${ }^{15}$ The breakdown of dentists registered with the Health Professions Council of South Africa (HPCSA) for 2015, according to age, gender and race, showed that younger dentists were predominantly female and Black while older dentists were mainly White and male. ${ }^{14}$

To empower the academic staff with the necessary pedagogical skills, ${ }^{9}$ the recommendation of the American Dental Education Association about mentoring ${ }^{16-20}$ becomes relevant to the RSA. Descriptions about mentorship "encompass a synergistic relationship between a mentor with accumulated expertise and a mentee with novice-like inexperience, who engage in the sharing of knowledge and personal experiences to facilitate career development and guidance towards a path of promotion, fulfilment and overall success ... lack of mentorship may result in failure to retain junior faculty at an institution or within academia altogether." [p2] ${ }^{18}$

In 2019, there were approximately 100 academics within the faculty, required to teach and provide dental care services in hospitals and communities. ${ }^{21}$ The profile of the academics reflected the general profile of those reistered with the HPCSA. ${ }^{14}$ Fifty-eight of the academics were in permanent full-time positions, eleven at professorial levels, and only 15 possessed PhD qualifications in addition to their professional qualifications. Within the first year of the mentor's (SLA) appointment, less than one third of 20 mentees consulted on issues about post-graduate studies and writing papers for publication. Others sought "guidance on coping with faculty demands".

\section{OBJECTIVES}

The absence of guidelines for effective mentoring programs in the faculty prompted the exploration of the perceptions of academics below professorial rank about the pilot mentoring program. The objectives were to evaluate the experiences of academics who engaged in (a) the EASCEP and (b) any other mentoring process after joining the faculty; and (c) the perceptions of academics about what a faculty mentoring program should focus on. To prevent a potential bias, a research assistant (RB) was appointed to independently manage the study process, at the end of which the analysed data was then checked and debated by the authors.

\section{METHOD}

\section{Procedure}

After obtaining ethics approval (BM19/9/15) and sourcing for funding from the Research Office of the university, a self-administered adapted questionnaire ${ }^{16,22}$ was pilot tested for face and content validity with five academics in the faculty. Using a cross-sectional, descriptive research design, RB later distributed the survey instrument via email and hard copies, among academics below professorial ranks $(n=89)$. The four-part survey instrument (Appendix 1) sought biographical information (9 items), perceptions about the EASCEP (4 items), experiences in any other mentoring processes after joining the faculty (12 items), and expectations of a future faculty mentoring program (24 items).

A cover letter accompanied the survey instrument, explaining the study procedures and the voluntary basis of participation. Unfortunately, the response was poor. Such development is not necessarily an unwillingness of academics in dental schools in the RSA to participate in research, but their responsibilities in teaching and service delivery are often obstacles. ${ }^{21} \mathrm{~A}$ purposive sampling, qualitative research design ${ }^{18,23-25}$ was then adopted to address the same aims. The twenty mentees who engaged in the EASCEP were targeted, but only eight consented. The amended four-part survey instrument (Appendix 2) was also administered by RB via individual, semi-structured interviews via Skype which took place in March 2020 during the COVID-19 pandemic. Part A of the survey instrument sought biographical information, while the remaining three parts sought participants' (i) perceptions about the EASCEP, (ii) experiences in other mentoring processes since joining the faculty, and (c) expectations about mentoring in the faculty.

Table 1. Profile of participants $(n=8)$.

\begin{tabular}{|c|c|c|c|c|}
\hline Participant & Age (years) & Highest qualification achieved & Position in faculty & Years in faculty \\
\hline A1 & 37 & Masters & Senior lecturer & 3 \\
\hline A2 & 52 & $\mathrm{PhD}$ & Senior Lecturer & 18 \\
\hline A3 & 55 & $\mathrm{PhD}$ & Senior lecturer/Assoc. Professor & 17 \\
\hline A4 & 47 & $\mathrm{PhD}$ & Assoc. Professor & 20 \\
\hline A6 & 45 & $\mathrm{PhD}$ & Senior Lecturer & $+/-20$ \\
\hline A7 & 59 & Masters & Biostatistician & 3 \\
\hline A9 & 59 & Masters & Senior Lecturer & 26 \\
\hline A10 & 42 & Masters & Senior Lecturer & 8 \\
\hline
\end{tabular}


The survey instrument was sent in advance to the eight participants so they could answer the closed-ended questions and have time to ponder on their responses to the open-ended statements. Unfortunately, only five of the participants (A2, A4, A6, A7, A9) were able to keep the interview appointments, while the remaining three (A1, A3, A10) completed and submitted the survey instrument (Appendix 2).

The demographics of the non-respondents were similar to those of the respondents presented in Table 1. The interviews were audio-recorded and transcribed. The data that support the findings of this study are available from the corresponding author upon reasonable request.

\section{Analyses}

Quantitative data was analysed descriptively, while content analysis of the qualitative data was performed by two independent academics with expertise in qualitative research to identify themes which were then discussed to reach consensus. ${ }^{23}$ To check and establish credibility in the findings, data were triangulated through (i) giving the participants access to the transcriptions for verification; (ii) comparing interview data alongside relevant academic literature; and (iii) agreement of the interpretations of the data by the researchers.

\section{FINDINGS}

Table 1 describes the profile of the participants. Two participants (A2, A3) had only brief interactions with the mentor and were unable to comment on the value of the mentorship program but presented their expectations about a future formal mentorship program in the faculty. Though A2 and A4 were not engaged in other mentoring processes since appointment, there was consensus among the participants about the purpose of mentoring as described by A9:

Understanding the mentee, providing a safe space for the mentees to share their plans, aspirations and challenges; assisting the mentee to reflect objectively on their challenges and aspirations, ...guiding the mentee to reach goals... to reflect [but] not creating dependence on the mentor.

Participants also differentiated a mentor from a supervisor:

...The supervisor... can guide you in the methodological process and has deep insight into your [research] topic... The mentor is [a] person I will [go to] if I need something my supervisor cannot give me, such as, someone to share my research experiences with..., when I need additional emotional support ... when I begin to chart unknown territory, when I need to bounce off ideas... when I need my morale as a researcher lifted, when my supervisor cannot provide me with all the skills I require, like writing support, selecting a journal ... a supervisor helps only with research related issues whilst a mentor can help with other factors such as promotion... or publication of an article. [A2]

Two themes emerged from the survey:

\section{'A Welcome Initiative'}

The mentoring program was perceived as necessary and a welcome initiative. A response that resonated with many of the participants was having 'a very positive experience' during consultations.

I think it is a very positive effect. It is nice to know there is someone there that you can bounce ideas off if you are not too sure. Especially if you are new with supervising PhD students. [A4]

... the entire process has been very positive ...I developed a lot of confidence. [A6]

On what worked well in the mentorship program, mentees described their experiences:

I think it was having somebody who was accessible. [A6]

The mentor listened and tried to understand where I was academically ... my work situation ... where my work fitted into my life situation. Also, that he followed up, that he wasn't very demanding, that he wasn't really in any way judgmental. He tried to help me make sense of where I was. [A9]

What I enjoyed was the open communication. We were able to bounce ideas off each other; could bounce ideas off someone else and see whether we are on the right track... [A4]

Having a sounding board, somebody to talk to you whenever I felt like I was stuck and needed advice that I wouldn't normally get from anybody else, to listen to me at that time because everybody is always at meetings or they have got to be... their primary focus is something else, rather than being there to help academically, or just to help staff when they have questions. It is always nice to have a bouncing board ... I always felt if I didn't know the answer that I would be guided to finding the right person or the right direction. [A7]

The mentor helped me to define and conceptualize my research idea. I feel guilty at times that I had not utilized the mentor to the fullest. [A10]

One on one sessions and meetings; step by step counselling $[\mathrm{A} 1]$

As to what did not work well, the experiences of two respondents related to time:

Due to my clinical and postgraduate engagements it was difficult to meet every time and complete tasks. [A1]

I still struggled to execute, and I suppose that time management is a problem for me that was not addressed. [A10]

The professional background of the mentor was a concern to one participant while two others perceived this was beneficial:

The mentor wasn't a dentist; so, context was always a 
problem and the mentor didn't have experience within the faculty. So, you always have to put context into it because things work differently at the dental faculty. [A7]

For me, I find it is often nice to have somebody from a different discipline to give you different insights because they see things differently and I think when you are in the same faculty it can be a little bit awkward. I think that really helped me a lot. In my experience I have found it very helpful to get somebody from the outside, from another discipline to see how they view things because we do things that are similar, but we have different approaches to it and different understandings. It is refreshing to learn different techniques to do the same thing. [A6] It is also good to speak with somebody that's not working with you directly and you know doesn't have any other expectations of you and simply sees you for what you are doing at that point. [A9]

Participants $A 1$ and $A 10$ also expressed similar views on what to improve in the mentoring process:

Allow employees to clear their undergraduate and postgraduate schedule for one day or a half a day to receive mentoring. [A1]

I think that respective mentees need to be identified and mentored to develop their career paths, including research, to ensure a sufficient number of suitably qualified personnel for succession planning; ...the process must be individualized and help to direct focus and use strengths and support areas of weakness ... some clear steps are to be jointly determined by the mentee and mentor, with clear short- and long-term deliverables. [A10]

Those involved in other mentorship networks, mostly initiated on their own accord, shared different experiences I had a mentor to assist with career pathing, the mentor was too busy to really assist me and we never worked on a jointly agreed upon plan of action, it was good to engage with someone from a different faculty, but little value in mentorship had been gained. Perhaps we were mismatched. [A10]

I think that there are many unofficial mentors [like] supervisor of my $P h D$... I regarded him as a mentor in that I could always go to him outside of the PhD and he would always have an open door. I think there is an almost unofficial system that is very healthy but sometimes not that healthy because you can end up being in a group where you have negative experiences and that drag you into a negative space. Therefore, a mentor that is almost outside of that, that can take you away from that is very good. In that way, I think, the current person has the potential to really support staff in different ways. [A9]

I had experience outside of the faculty for many years with one of the professors ... If there was anything I would need, guidance as to how to apply for the current position I have, or if I have any issue. I have two mentors inside the faculty besides the funded mentor. It has been a very positive and uplifting experience. I feel that I have gained a lot from all these people. [A7]

I think previously, during my $\mathrm{PhD}$ I was part of a program which was for PhD students. We weren't assigned mentors formally but within the group we mentored each other through the whole process of doing the PhD. So that was very helpful. For me it was a lonely process because at the time, within the faculty, there were very few people doing PhDs and none of my peers was doing a PhD. [A6]

\section{'Mentorship seen as a holistic experience - A career friend'}

The participants strongly expressed the need for a formal mentorship program within the faculty, which should be holistic in nature for optimum use and success. As for their expectations from a future formal faculty mentorship program, one participant explained it clearly:

There is a lack at the faculty, in terms of support; there is a lack in terms of work and how you are supported in coping with the many roles you have. [A9]

Participants expressed their expectations from a future formal mentorship program:

I will tell you why, up until now I am still struggling to get an article out of my PhD program, simply because I don't have mentorship. Doing a PhD is very different from writing a journal article, I am up and running with my writing again, but I still feel that I am lacking in mentoring for that process. I never had that, and I am learning from scratch and unfortunately it has taken the life out of me because I become so frustrated and dejected at times. A mentorship program is needed. Not only for the PhD [and] Masters process but also for the process after that, what happens afterwards. [A2]

The mentor should be actively involved in teaching us new skills and knowledge. ... should be able to listen and give constructive feedback. [A1]

Someone to guide you to improve your position within the faculty.... impacts on your development, someone who improves your knowledge about faculty related issues. [A3]

The mentor can basically just guide you to make sure that you make use of the opportunities that are available to you. We often get emails about opportunities. I think... if you are starting out in a lecturer position it is very helpful to have that type of guidance that is formal, because I think then we are capacitating staff a lot easier and the staff development can be more structured and more meaningful rather than just doing odd ad hoc things. [A6]

It's just teaching you things that people expect you to just know, a role of a mentor. It is not just academic, its social and its psychological. It is not easy. Being in the dental faculty is not easy, being in academia is not easy but being in [this] dental faculty is exceptionally not easy ... you still feel it. Just somebody who can be your sort of career friend... so it's not just about furthering my career in a hard way but in soft skills as well. [A7]

Whatever, it might be good if that person has an idea to say this is the expectations of this institution of you and how can I help you, or support you to develop your own 
career plan, or your plan that you actually meet these requirements.... there must be some space where the person knows the expectations and can guide you to say, maybe you need to speak to the faculty about these other things that is making it difficult for you. [A9]

Just talking to someone sometimes triggers other ideas, like I could have done it that way, that's not a bad idea. I could maybe try something else. So just getting a different perspective might trigger other ideas or other ways of doing things. That's also good. Just talking about it helps, so that is very valuable when it comes to the mentorship... [A4]

Define short- and long-term goals and purpose for the mentorship. Determine deliverables to meet those goals at reasonable intervals. An analysis is required of each mentee to determine what the real need of support may be to identify stumbling blocks to execution and impart skills to overcome those to ensure delivery of goals, both short and long term. [A10]

Different ways of developing the mentorship program were suggested:

I recommend a panel of mentors ... spearheaded by [a] Professor... the panel can actually sit in on maybe the research committee that sits twice a month... so that panel should actually feed into the research committee. It is something we are really, really lacking in the faculty. [A2]

I actually think that it would be helpful for somebody coming ... into academics for the first time ... assign them a mentor as part of their probation period ... it would be very helpful because often we don't really have a plan when you start out as a lecturer. [A6]

For maximum reach to a wider range of staff members, it was suggested that the mentorship program be introduced to the staff in a different manner:

To be honest with you, it needs to be advertised. You need to widely tell the staff and the students this is what is available. I will be honest, I heard about it but it was not spelt out to us in no uncertain terms this is what is available to us. I didn't even know until this interview process that this is the kind of mentoring capacity we have in the faculty. I was astounded, and I quickly wrote an email to Prof and said I need help ... So, as you can see, I think it needs to be spelt out with clear terms of reference. [A2]

I think [the] faculty should have introduced the mentor differently... I think it was very much left to staff by word of mouth, to say "have you met with the mentor because he is really helpful". So, if I [did not hear this] I probably wouldn't have bothered, and I think I would have lost a good opportunity. I think where it can improve is to get the faculty board to actually introduce the mentor to staff and maybe the mentor do a presentation of, this is who I am, this is the work I have done, this is what I can offer so that it is out there to the staff. I don't think it worked that well putting an email out because I think it depended very much on word of mouth. I think more people could have been reached. [A9]

\section{DISCUSSION}

This study set out to evaluate the experiences of academics in the Faculty of Dentistry at UWC who engaged in the EASCEP, as well as their expectations from a future formal program. The change in methodology due to the poor response in the first survey did not compromise the integrity of this study as similar methodologies have been utilized in previous studies. ${ }^{18,23-25}$ However, the poor participation of academics in research ${ }^{21}$ may be a reflection of their inability to satisfactorily share their time in meeting the demands in teaching, research, clinical service and administration.

The participants also acknowledged that it was essential to allocate time to participate in the mentorship process. Upon entering a career in dental education, the academic is expected to successfully navigate an oftenunfamiliar environment of teaching, scholarly activity and research, as well as perform administrative tasks and participate in both university and community service. ${ }^{18}$ Academics may also need assistance to manage the time to meet these demands. With little or no previous experience and coming from diverse backgrounds, the new academic may become overwhelmed, unsupported, and discouraged.

Currently, there is little documented evidence of specific formal activities relating to mentorship of academic staff in Dental faculties in RSA. Though the pilot program targeted academics yet to obtain a doctoral degree or below professorial rank, it was accessible to all academic staff. So, it is worth noting that two participants who had not engaged in any mentorship process had been in the faculty for 18 and 20 years respectively. Such occurrence acknowledges the need for a formal mentorship process to help new lecturers in their transition into their new positions, ${ }^{18}$ especially in a faculty where the demographic profile of the lecturers is still similar to the profile of those registered with the HPCSA in $2015 .{ }^{14}$

Overall, the EASCEP was perceived as a necessary and welcome initiative as in other studies. ${ }^{16-20}$ On what worked well in the mentorship program, mentees perceived the consultation provided the much-needed space, where they felt they were heard and understood to seek the required support and guidance in respect to academic development. Participants appreciated the accessibility of the mentor and the individual attention they received. However, it should be noted that there were no discipline-specific issues raised with the mentor, though it is uncertain if this was due to the mentor not having a background in dentistry.

Participants were clear in what they expected from a formal mentorship program stemming from what seemed to be lacking within the faculty. The expectations were broader than what was being addressed in the EASCEP and included seeking assistance to meet faculty and institutional demands. As the unique context of each institution and the diverse needs of each academic will 
impact on how the capacity development of academics is managed, an ideal mentorship program should address both the professional and the personal development of academics. ${ }^{10}$ To enhance the accessibility of the mentorship program, the mentees in the EASCEP recommended ways to improve the advertisement of such a program. Thomas et al. recommended that administrators of mentorship programs might consider publicising the programs in advance of the academic year in which the programs are offered. ${ }^{25}$ The recruitment materials should also be explicit regarding what is expected of the participants, as well as what benefits they may expect. In addition, due consideration should be given to train potential mentors.

\section{CONCLUSIONS}

There is evidence that the UCDG mentorship program has been beneficial to those individuals who participated in the process. There is also the expectation that a formal mentorship program within the Dental Faculty at UWC is critical in the career development of the academic staff.

\section{Acknowledgments}

The authors acknowledge the grant from the Research Department, University of the Western Cape.

\section{Declaration of interest statement}

The authors do not have any potential conflict of interest.

\section{References}

1. Leibowitz B, Bozalek V, van Schalkwyk S, Winberg C. Institutional context matters: the professional development of academics as teachers in South African higher education. High Educ. 2015; 69: 315-30.

2. South African Government. National Development Plan 2030, in Improving education, training and innovation. 2011; 295-328.

3. Academy of Science of South Africa (ASSAf). Twelve years later: Second ASSAf report on research publishing in and from South Africa. 2018. doi:10.17159/assaf.2018/0030, 2019 [Accessed 23/05/2019]

4. Department of Higher Education and Training. Staffing South Africa's Universities Framework - A comprehensive, transformative approach to developing future generations of academics and building staff capacity, 2015. Retrieved from http:// www.justice.gov.za/commissions/FeesHET/docs/2015-Staffing-SAUniversitiesFramework.pdf.

5. Department of Higher Education and Training. University Capacity Development Programme; Implementation plan for the entrepreneurship development in higher education (EDHE) programme 2018-2020. Retrieved from http://entrepreneurship. uwc.ac.za/wp-content/uploads/2018/04/UCDP_Plan_ EDHE-high-level-.pdf.

6. Mouton J. Doctoral production in South Africa: Statistics, challenges and responses. Perspect Educ. 2011; 29(3): 13-29.

7. Moja T, Hayward FM. The changing face of redress in South African higher education (1990-2005). Journal of Higher Education in Africa 2005; 3(3): 31-56.

8. University of the Western Cape (UWC). History of UWC, 2020. Retrieved from: <https://www.uwc.ac.za/Pages/History.aspx>.

9. Ndebele C, van Heerden J, Chabaya O. Development and implementation of a mentoring programme at a historically disadvantaged South African university. J Soc Sci. 2013; 34(2): 123-33.
10. Mclean M, Cilliers F, van Wy JM. Faculty development: Yesterday, today and tomorrow. Med Teach. 2008; 30: 555-84.

11. Cleaton-Jones P, Volchansky A, Copland L. Epidemiological profile of graduates of the Wits Dental Faculty 1927-1995. S. Afr Dent J. 1996; 51: 721-5.

12. Taljaard LT. Dental education in relation to the needs of the South African community. Int J Dent. 1977; 27(1): 1-9.

13. O'Connell BP. Message from the Rector. S Afr Dent J. 2009; 64(10): 428.

14. Bhayat $A$, Chikte $U$. The changing demographic profile of dentists and dental specialists in South Africa: 2002-2015. Int J Dent. 2018; 68: 91-6.

15. Bhayat A, Chikte U. Human resources for Oral Health Care in South Africa: A 2018 update. Int J Environ Res. Public Health 2019; 16: 1668.

16. Bagramian RA, Taichman RS, McCauley L, Green TG, Inglehart MR. Mentoring of dental and dental hygiene faculty: A case study. J Dent Educ. 2011; 75(3): 291-9.

17. Tax CL, Doucette H, Neish NR, Maillet JP. A model for cultivating Dental Hygiene Faculty development within a community of practice. J Dent Educ. 2012; 76(3): 311-21.

18. Bartle EK, Crivello BJ, Bullock JL, Ogbureke El. Mentorship availability and needs for junior faculty members at the United States and Australian dental schools. Eur J Dent Educ. 2020; 00: 1-9. https://doi. org/10.1111/eje.12570.

19. Al-Jewair T, Herbert AK, Leggitt VL, Ware TL, Hogge M, Senior C, Carr RK, Da Silva JD. Evaluation of faculty mentoring practices in seven U.S. Dental Schools. J Dent Educ. 2019; 83(12): 1392-1401.

20. Gadbury-Amyot CC, Smith DB, Overman PR, Bunce L. Faculty development at one Midwestern Dental School: A programme evaluation. J Dent Educ. 2015; 79(10): 1177-88.

21. Grossman ES, Naidoo S. Academic-service partnerships, research, and the South African dental academic. J Dent Educ. 2012; 76(9): 1226-33.

22. Schulze S. Mentees' views of a structured mentoring programme at Unisa. S Afr J High Educ. 2010; 24(5): 782-99.

23. Edmunds S, Brown G. Doing qualitative research in dentistry and dental education. Eur J Dent Educ. 2012; 16(2): 110-7.

24. Kasule GW, Wesselink R, Mulder M. Professional development status of teaching staff in a Ugandan public university. J High Educ Policy Manag. 2016; 38(4): 434-47.

25. Thomas JD, Lunsford LG, Rodrigues HA. Early career academic staff support: evaluating mentoring networks. J High Educ Policy Manag. 2015; 37(3): 320-9. 